\title{
Kraniomandibuläres und Muskuloskelettales System: Funktionelle Konzepte in der Zahnmedizin, Kieferorthopädie und Manualmedizin
}

\section{Wolfgang Boisserée, Werner Schupp}

Publisher: Quintessenz Verlag

Language: German

ISBN: 978-3-86867-110-0

Edition: 1/e

Publish Year: 2012

Pages: 432, illustrated

Price: $198,00 €$

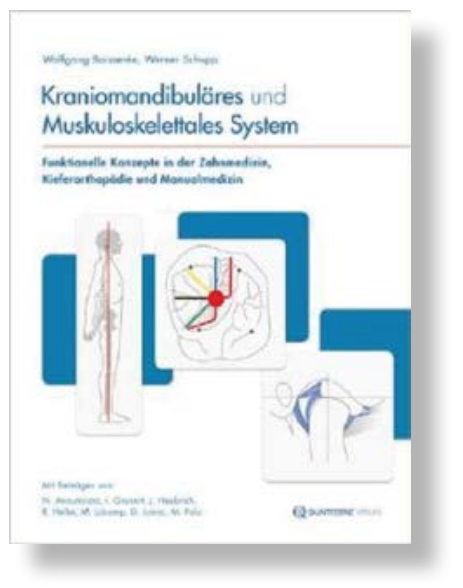

Functional therapy.

The book "Craniomandibular and

Musculoskeletal System: Functional Concepts in Dentistry, Orthodontics and Manual Medicine" by Wolfgang Boisserée and Werner Schupp presents a focussed and practical approach on functional diagnostics and therapy that takes into account the complex interactions between the craniomandibular and musculoskeletal system. The craniomandibular dysfunction causes can be found in different medical fields, internal medicine, orthopedics, neurology, otorhinolaryngology, psychology, thus requring a multi- and inter-disciplinary approach of the patients with craniomandibular disorders. They bring together medical specialties and dental disciplines, orthodontics, restorative dentistry and prosthetics to make a correct diagnosis and initiate an effective treatment.

The book is divided into four parts: The craniomandibular system (CMS) and its relationships with the musculoskeletal system (MSS), Dysfunction of the craniomandibular system (CMS), the diagnostic concept, and
The relation between the craniomandibular system and the musculoskeletal one is covered in the first part of the book over six chapters.

Part two describes in depth the characteristics, physiology and pathology of the craniomandibular system in five chapters.

The diagnostic concept, the third part of the book, presents, in four chapters, topics such as patient history, intraoral examination, diagnostic imaging and clinical, instrumental and functional diagnosis.

The last part, functional therapy, has eight chapters with a variety of illustrations and examples, giving descriptive instructions for the successful treatment of the craniomandibular dysfunction by manual medicine, orthodontic, restorative and prosthetic treatment techniques. This 418 page-bookhasamoderninterdisciplinary approach on the craniomandibular dysfunction (CMD) illustrating in its more than 1400 images a functional concept integrating the craniomandibular and musculoskeletal systems. 